\title{
Enteric Manifestations of Cowden Syndrome
}

\author{
Konosuke Nakaji ${ }^{1}$, Yukinori Nakae ${ }^{1}$ and Shigeo Suzumura ${ }^{2}$
}

Key words: enteric manifestations, Cowden syndrome

(Inter Med 49: 795-796, 2010)

(DOI: 10.2169/internalmedicine.49.3063)
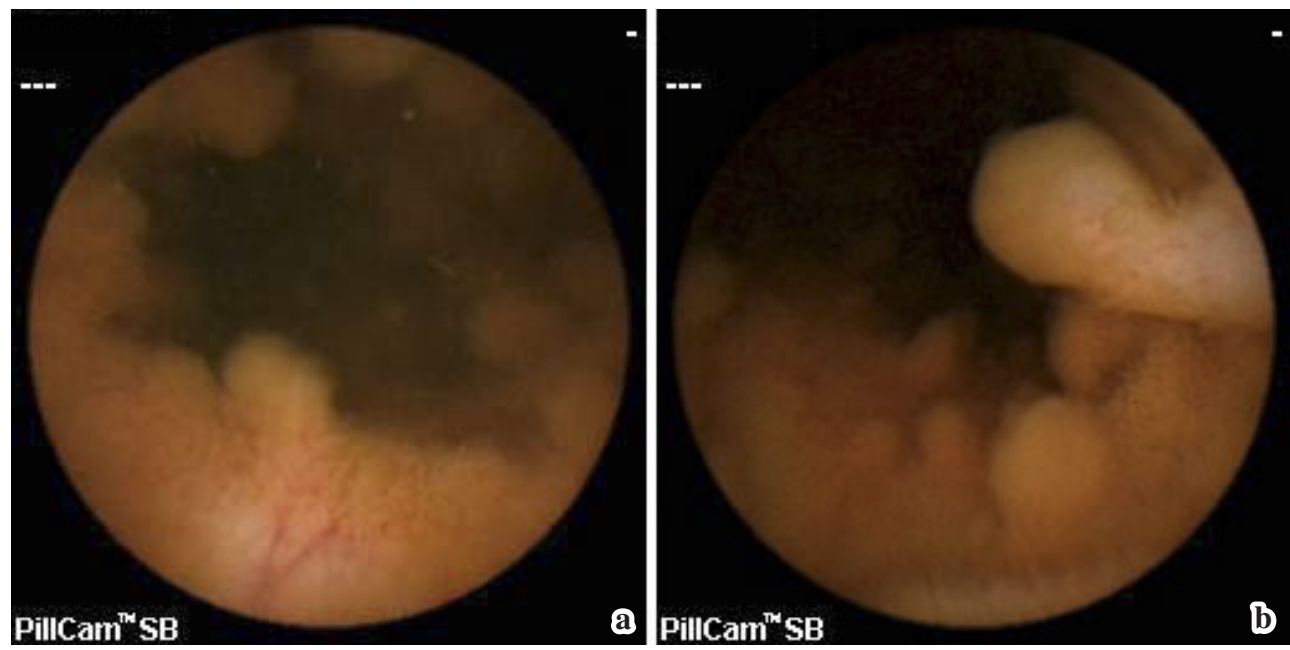

Picture 1a, b. Capsule endoscopy in the small intestine revealed multiple polyps which ranged from 3 to $5 \mathrm{~mm}$.

A 24-year-old Japanese man was admitted to our hospital for an annual check-up of gastrointestinal polyposis. He had previously fulfilled the diagnostic criteria of international Cowden Consortium (Version 2000) (1), and had been diagnosed as having Cowden syndrome (CS) at the age of 18 . His father was diagnosed as having Cowden syndrome. Their physical examinations revealed cutaneous facial papules, oral mucosal papillomatosis, and gastrointestinal polyposis. Genetic analysis has not been performed because of family's request. Upper gastrointestinal endoscopy showed the presence of whitish polypoid lesions in the esophagus as well as in the stomach and duodenum.

The esophageal polyps were diagnosed histopathologically as glycogenic acanthosis. The gastric polyps showed hamartomatous changes and epithelial hyperplasia. The duodenum polyps showed lymphoid papillomas. Colonoscopy showed multiple polyps in the terminal ileum, colon and rectum. The biopsy specimens of these lesions showed reactive lymphoid hyperplasia.
Capsule endoscopy revealed multiple polypoid lesions lesions the diameter of which ranged from 3 to $5 \mathrm{~mm}$ (Picture $1 \mathrm{a}, \mathrm{b})$. The number of these polyps increased from the jejunum to the terminal ileum.

CS is a rare condition, and it was estimated to be as low as one in 1,000,000. It is usually inherited as an autosomal dominant condition and is a multi-system disease involving hamartomatous overgrowth of tissues of all three embryonic origins (2).

Hamartomatous polyps occur throughout the GI tract and were originally estimated to occur in $60 \%$ of affected individuals (2). In a review of CS cases, the most common sites for GI polyps included stomach (75\%), colon (66\%), esophagus $(66 \%)$, and duodenum (37\%) (2).

Small-bowel polyps also occur in CS. However, these polyps are difficult to detect with conventional techniques including double contrast Xray study, because the size of polyps is considerably small and they do not protrude much.

We herein report novel findings of small intestine with

${ }^{1}$ Internal Medicine, Aishinkai Nakae Hospital, Wakayama and ${ }^{2}$ Division of Epidemiology, Department of Cancer Control and Statistics, Oasaka Medical Center for Cancer and Cardiovascular Diseases, Osaka

Received for publication October 25, 2009; Accepted for publication January 21, 2010

Correspondence to Dr. Konosuke Nakaji, ko_9.so-pa1bm2is@akk.view21.net 
capsule endoscopy in a Japanese CS patient.

\section{References}

1. Umemura K, Takagi S, Ishigaki Y, et al. Gastrointestinal polyposis with esophageal polyposis is useful for early diagnosis of Cowden's disease. World J Gastroenterol 14: 5755-5759, 2008.
2. Gammon A, Jasperson K, Kohlmann W, Burt RW. Hamartomatous polyposis syndromes. Best Pract Res Clin Gastroenterol 23: 219231, 2009.

(C) 2010 The Japanese Society of Internal Medicine http://www.naika.or.jp/imindex.html 